7-6-2015

\title{
Talk matters at work: The effects of leader member conversational quality and communication frequency on work role stressors
}

\author{
Guowei Jian \\ Cleveland State University, g.jian@csuohio.edu \\ Francis Dalisay \\ University of Hawaii, Manoa, fdalisay@gmail.com
}

Follow this and additional works at: https://engagedscholarship.csuohio.edu/clcom_facpub

Part of the Interpersonal and Small Group Communication Commons, and the Organizational

\section{Communication Commons}

How does access to this work benefit you? Let us know!

\section{Publisher's Statement}

Guowei Jian \& Francis Dalisay, Talk Matters at Work: The Effects of Leader-Member Conversational Quality and Communication Frequency on Work Role Stressors. International Journal of Business Communication (Published online before print) pp. 1-18. Copyright (C) 2015 by Association of Business Communication. Reprinted by permission from Sage Publications, Inc.

\section{Recommended Citation}

Jian, G. \& Dalisay, F. (2015). Talk matters at work: The effects of leader-member conversational quality and communication frequency on work role stressors. International Journal of Business Communication. Advance online publication. doi:10.1177/2329488415594157

This Article is brought to you for free and open access by the School of Communication at EngagedScholarship@CSU. It has been accepted for inclusion in Communication Faculty Publications by an authorized administrator of EngagedScholarship@CSU. For more information, please contact library.es@csuohio.edu. 


\title{
Talk Matters at Work: The Effects of Leader-Member Conversational Quality and Communication Frequency on Work Role Stressors
}

\author{
Guowei Jian' and Francis Dalisay²
}

\begin{abstract}
Although it is clear that leadership plays a significant role in followers' psychological health, the specific mechanisms by which leadership effects may take place await further theorizing and investigation. We argue that communication practices may constitute such specific mechanisms. Therefore, the purpose of this study is to examine how leader-member conversational quality (LMCQ) and communication frequency are associated with members' perception of work role stressors. Through an online survey, the study found that LMCQ has a significant predictive effect on work role ambiguity and role overload. However, LMCQ interacts with communication frequency in their effects on role conflict. These findings contribute to theories of leadership communication and the continuous development of role dynamics theory.
\end{abstract}

\section{Keywords}

leadership, leadership communication, supervisory communication, work stress, role stressors

Research in occupational medicine continues to reveal the negative effects of work stress on employee work outcomes (Rosen, Chang, Djurdjevic, \& Eatough, 2010), adverse health behaviors (Kouvonen et al., 2007) and both short-term and longterm mental and physical well-being (Nixon, Mazzola, Bauer, Krueger, \& Spector,

'Cleveland State University, Cleveland, $\mathrm{OH}$, USA

¿University of Guam, Mangilao, GU, USA

Corresponding Author:

Guowei Jian, Cleveland State University, 212 I Euclid Avenue MU247, Cleveland, OH 44I43, USA.

Email: g.jian@csuohio.edu 
2011; Perrewé \& Ganster, 2006, 2010). Role stressors are among the most common sources of work strain and burnout that employees experience on a routine basis. Over the years, scholars in communication and other disciplines have identified a few variables that are associated with role stressors, such as social support (e.g., Nissly, Mor Barak, \& Levin, 2005; Ray \& Miller, 1991) and job demands and control (e.g., Fox, Dwyer, \& Ganster, 1993). In particular, research suggests that leadership plays a significant role in affecting follower psychological health (Macik-Frey, Quick, \& Nelson, 2007). However, as Macik-Frey et al. (2007) pointed out, more precise mechanisms by which leadership is associated with follower psychological outcomes have to be investigated. We argue that recent studies regarding conversation in organizational and business communication research may present an opportunity to further this line of research.

Taking a social constructionist approach, a growing body of literature (e.g., Boden, 1994; Clifton, 2012; Taylor \& Van Every, 2000) on organizational conversation has convincingly demonstrated the constitutive power of conversation in the process of organizing. In the field of managerial communication, empirical studies based on motivation language theory (Sullivan, 1988) have demonstrated significant predictive effects of leader speech acts on such employee work outcomes as absenteeism (Mayfield \& Mayfield, 2009), job satisfaction (Mayfield \& Mayfield, 2006; Sharbrough, Simmons, \& Cantrill, 2006), and self-efficacy (Mayfield \& Mayfield, 2012). Within the framework of leader-member exchange, previous research has shown that leader-member relationship quality is significantly associated with members' role perceptions (Graen \& Uhl-Bien, 1995). Inspired by these developments and also drawing on interactional richness theory (Barry \& Crant, 2000) and the theory of role dynamics (Kahn, Wolfe, Quinn, \& Snoek, 1964), we argue that an examination of leader-member conversations may reveal important pathways that connect to follower perceptions of role stressors. More specifically, the present study intends to examine the association between leader-member conversational quality (LMCQ) and subordinate perceived role stressors.

The contributions of this study are threefold. First, the findings extend the theory of role dynamics by specifying communicative practices that are associated with role stressors. Second, the study offers quantitative evidence that demonstrates the importance of routine work conversations in shaping individual outcomes. Previous studies of work conversations often took the form of in-depth qualitative investigations, such as discourse analysis (e.g., Fairhurst, 1993; Jian, 2011). The findings of this study complement previous research in building a fuller understanding of routine work conversations and their organizational correlates. Third, from a practical standpoint, the findings provide employees in the workplace, and professionals in occupational health, with concrete guidance with regard to alleviating and managing role stressors through communicative practices.

The next section presents the theoretical foundations for this study and proposes several hypotheses. This is then followed by sections that detail the methods and results of the empirical testing of the hypotheses through an online survey study. The final section concludes with a discussion of the theoretical and practical implications 
of the findings together with a reflection of the limitations and directions for future research.

\section{Theory and Hypotheses}

\section{Work Role Stressors}

Work stress is composed of multiple sources (Rosen et al., 2010). Of particular interest in this study are the sources of stress related to work roles known as role stressors. The theory of role dynamics serves as the foundation for understanding role stressors (Kahn et al., 1964). According to the theory, a working individual has an implicitly or explicitly assigned role in an organization or a set of activities he or she is expected and/or demanded to perform. These role expectations and demands generate pressure or stress over the performing individual. According to their varied nature and quality, role stressors are differentiated into three types: role ambiguity, role conflict, and role overload. Kahn et al. (1964) and Rizzo, House, and Lirtzman (1970) refer to role ambiguity as the level of certainty and clarity an employee perceives with regard to his or her role's responsibility, expectations, and evaluations. Role conflict refers to the contradictory assignments, inconsistent expectations, or competing obligations experienced by an employee. In Kahn et al.'s (1964) initial conceptualization, the third role stressor, role overload was considered a particular type of role conflict. However, later studies (Glazer \& Beehr, 2005; Tordera, González-Romá, \& Peiró, 2008) suggested role overload, although having a high correlation with role conflict, have its unique quality. Role overload is defined by the degree to which an employee perceives his or her assignments or expectations as exceeding what his or her ability affords to handle with available resources without compromising quality (Jian, 2014; Tordera et al., 2008).

Since Kahn et al.'s (1964) seminal work, an impressive amount of research on role stressors has accumulated over the years, identifying negative associations of role stressors with work performance (e.g., Rosen et al., 2010) and attitudinal outcomes, such as job satisfaction and organizational commitment (e.g., Antón, 2009). For example, a meta-analysis of 169 sample studies found that job performance is negatively correlated with all role stressors, and its relationship with role ambiguity is most pronounced (Gilboa, Shirom, Fried, \& Cooper, 2008).

Another line of research made efforts to identify antecedents and correlates that may contribute to the perception of role stressors, focusing on variables related to alleviating stress and devising effective interventions. One consistent finding in this line of research suggests that social support from coworkers and supervisors, feedback, and participation in decision making are significantly associated with perceived levels of role stressors (Miller, Ellis, Zook, \& Lyles, 1990; Ray \& Miller, 1991).

In spite of these significant findings, we argue that more could be learned about role stressors by taking a closer look at communication in routine work settings through focusing on routine conversations and interactions that take place at work. Routine conversations at work are important, first, because both conceptual (Taylor \& Van 
Every, 2000) and empirical research (Boden, 1994; Clifton, 2012) in organizational communication in recent years has gradually revealed the central role of conversations in the process of organizing. More important, according to the theory of role dynamics, role expectations and demands are communicated from role senders to their receivers largely through conversations. We argue that the quality of conversation may affect how role expectations are perceived. Second, knowing the precise mechanisms by which communication works in relation to stress could offer concrete behavioral guidance for practitioners in managing and alleviating stress. The present study focuses on work conversations between leaders and members. The following section offers theoretical rationale for our focus and proposes several hypotheses.

\section{Leader-Member Conversation and Role Stressors}

In their comprehensive review of research on occupational health, Macik-Frey et al. (2007) suggested that leadership be a promising area that may offer significant understanding regarding follower psychological health. The authoritative position a leader often occupies in providing resources, defining roles, and evaluating performance of their followers has led scholars to focus on leadership as a key explanation for follower psychological health (e.g., Britt, Davison, Bliese, \& Castro, 2004). Studies have linked certain leadership styles to follower well-being. For example, in an experimental study, Lyons and Schneider (2009) found that participants exposed to a transformational leadership style would perceive a stressful task as less threatening than those exposed to transactional leaders. In a review of research conducted in military settings, Britt et al. (2004) observed that leader behaviors help reduce group conflict and followers' perception of role ambiguity, and increase their perception of contribution to a mission.

In spite of these findings on the association between leadership roles and followers' psychological health, Macik-Frey et al. (2007) critiqued in their review of this literature, "[t]here has been little study of the processes whereby leadership affects follower well-being in terms of specifying precise mechanisms" (p. 825). While an examination of an exhaustive set of mechanisms is beyond the scope of a single study, we contend that a detailed look at leader-member conversations would be an appropriate starting point in formulating the precise mechanisms that Macik-Frey et al. (2007) suggested.

First, we draw on the theory of leader-member exchange (LMX) as a framework for understanding leadership (Graen \& Uhl-Bien, 1995). Although defining leadership is a contentious issue in the broader literature of leadership, the majority of empirical LMX studies defines and operationalizes leader-member relationship within the context of supervisor-subordinate relationship in organizational settings. Thus, the terms supervisor-subordinate and leader-member are used interchangeably and leadership is narrowly defined by the formal supervisory position. The present study follows this tradition. The LMX theory lends its focus on the relational dynamic in leader-member dyads. It postulates that leaders develop varied levels of relationship quality with their members. Particularly, meta-analyses of LMX studies have presented strong evidence that lower LMX quality is associated with higher levels of member perceived role 
ambiguity and role conflict (Dulebohn, Bommer, Liden, Brouer, \& Ferris, 2012; Gerstner \& Day, 1997). However, LMX, being a perceptual assessment of overall relational quality, lacks the specificity in pinpointing the communicative process that may affect role stressors (Jian, Shi, \& Dalisay, 2014). In contrast, a focus on leadermember conversation reflects a more specified look at the communicative exchange. The focus on leader-member conversations also has its roots in the interaction richness theory, as articulated by Barry and Crant (2000). Interaction richness theory conceptualizes communication as both information exchange and meaning sharing. The theory argues that a rich interaction is one in which "communication within an interacting dyad at a given point in time is efficient (high in symbolic content), coordinated (characterized by synchronous interaction), and accurate (symbolic meaning is shared and appropriately interpreted)" (Barry \& Crant, 2000, p. 651). In a quality conversation, more meaning can be conveyed with fewer words; the interactional movements are highly synchronized; intended meanings conveyed by one partner are precisely interpreted by the other. We extend this to the context of leader-member conversations. In assigning a work task, for example, a high-quality conversation in a leader-member dyad should have a high degree of "carrying capacity" (Barry \& Crant, 2000, p. 651) in the sense that the interactional moment allows the sharing of this task assignment efficiently and accurately in a highly coordinated manner.

In addition, our focus on leader-member conversation is informed by recent studies on the effects of leader motivating language on follower outcomes. Drawing on speech act theory (Austin, 1962), Sullivan (1988) argues that leader language not only acts to reduce follower uncertainty through transmission of information but also to facilitate follower's meaning making and to establish human bonding. It is argued that these leader speech acts exert motivational forces on follower performance and psychological outcomes. Subsequent empirical research has lent strong support to the theory. For example, in a series of studies, it was found that leader motivating language is strongly associated with the reduction of employee absenteeism (Mayfield \& Mayfield, 2009) and with improvement in employee self-efficacy and performance (Mayfield \& Mayfield, 2012) and job satisfaction (Mayfield \& Mayfield, 2006). Sharbrough, Simmons, and Cantrill (2006) reported that leader motivating language is significantly correlated with member perception of job satisfaction, communication satisfaction, leader effectiveness, and leader's communication competency.

Based on these different bodies of literature on leadership communication, we argue that the quality of leader-member conversations has significant implications on subordinate perceptions of role stressors. If conversations are of high quality, with other factors being equal, we would expect a lower level of perceived role ambiguity on the part of subordinates, because high-quality conversations should convey expectations with more clarity. In a leader-member dyad, a high-quality interaction is not simply about the flow of messages from supervisors to subordinates but also how messages flow the other way around. In other words, the leader-member dyad develops a synchronized co-orientation toward mutual understanding. Because of such co-orientation, a high-quality conversation would allow a robust feedback mechanism in the dyad so that problems and questions regarding conflict or excessive work assignments 
tend to be detected and brought to resolution. As a result, members who perceive to have had higher quality conversations with their supervisors tend to perceive lower levels of role ambiguity, role conflict, and role overload. Hence, we propose the following hypotheses:

Hypothesis 1: Member-perceived conversational quality in a leader-member dyad is negatively associated with the member's perceived role ambiguity.

Hypothesis 2: Member-perceived conversational quality in a leader-member dyad is negatively associated with the member's perceived role conflict.

Hypothesis 3: Member-perceived conversational quality in a leader-member dyad is negatively associated with the member's perceived role overload.

In addition to conversational quality, communication frequency has drawn scholarly attention as an important communication factor that is associated with organizational and employee outcomes, especially within the leader-member context (Becerra \& Gupta, 2003; Gajendran \& Joshi, 2012; Kacmar, Witt, Zivnuska, \& Gully, 2003). For example, in a study of globally distributed teams, Gajendran and Joshi (2012) observed that communication frequency between team leaders moderates the association between leader-member relationship and member influence on team decisions such that, when communication frequency increases, the association is strengthened. The moderating effect of communication frequency was also found in a study by Becerra and Gupta (2003) on trust in organizational settings. For instance, their study revealed that, as communication frequency increased, an organizational member's attitudinal predispositions toward his or her colleagues became less important in determining his or her evaluation of their trustworthiness (Becerra \& Gupta, 2003). Based on existing research, it is reasonable to expect a moderating effect of communication frequency on the association between LMCQ and members' perception of role stressors. The rationale is that when communication frequency is low, the dyad may not be able to fully reap the benefit of quality conversations. However, when communication frequency increases, the effects of quality conversations become greater in lowering the perception of role stressors. Hence, we propose the following hypotheses. Figure 1 presents a conceptual diagram depicting the hypothesized moderating effects of communication frequency on the association of LMCQ with three role stressors.

Hypothesis 4: The association between LMCQ and member perception of role ambiguity is on the condition of leader-member communication frequency, such that the association is stronger when communication frequency is high than when communication frequency is low.

Hypothesis 5: The association between LMCQ and member perception of role conflict is on the condition of leader-member communication frequency, such that the association is stronger when communication frequency is high than when communication frequency is low.

Hypothesis 6: The association between LMCQ and member perception of role overload is on the condition of leader-member communication frequency, such that 


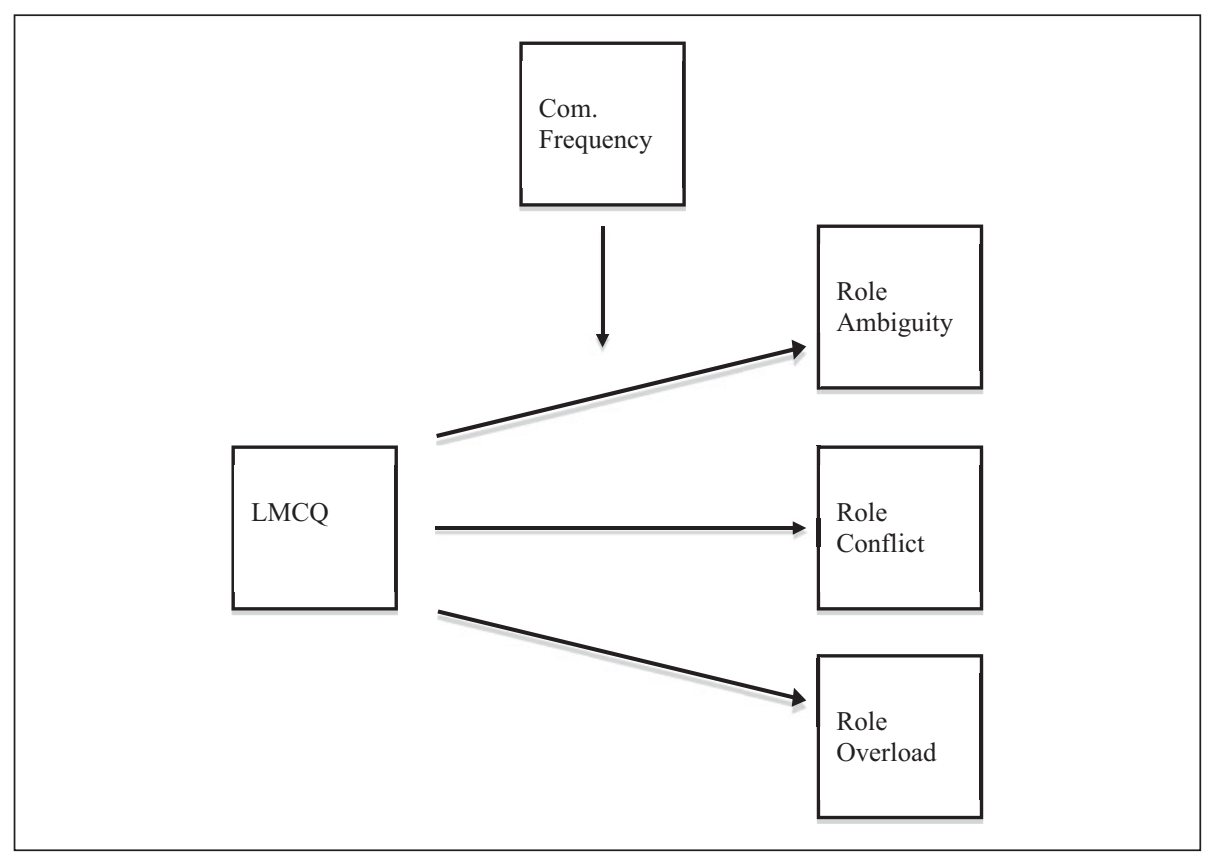

Figure I. A conceptual diagram of the hypothesized moderating effect of communication frequency on the association between leader-member conversational quality (LMCQ) and role stressors.

the association is stronger when communication frequency is high than when communication frequency is low.

\section{Method}

\section{Sample and Data Collection}

The study was part of a larger study on foreign-born employees working in the United States. It employed an online survey method for data collection. We adopted the definition of "foreign born" by the U.S. Bureau of Labor Statistics (BLS, 2013), which refers to those who reside in the United States but were born "outside of the U.S. or one of its outlying areas such as Puerto Rico or Guam, to parents neither of whom was a U.S. citizen" (p. 5). Because of the challenges in reaching a large number of foreignborn employees at one time, we adopted a network sampling strategy. In exchange for extra credit, students, who were enrolled in the undergraduate classes of the school of communication in a public university in a large Midwestern metropolitan area, were asked to refer an online survey to potential participants in their social networks who were foreign-born and currently employed in a U.S. organization with a direct supervisor. We invited 263 students and received 262 survey responses in total. Following 
Jian et al. (2014), as a deterrent against referral protocol violation on the part of students, we asked students to supply their referral's contact information, and, in the survey, participants were asked to supply the name of the student who referred them to the study. Also, to make sure that participants met the survey criteria, we included survey items to identify employment status and generational identity (foreign-born or later generation of immigrants). After deleting incomplete surveys and cases that did not meet the basic criteria for participation, 145 cases were retained for analysis.

In this sample, $55 \%$ were men and $45 \%$ women with a median age of 29 years $(M=34)$. The median organizational tenure of survey participants was about 3 years $(M=4.77)$ and median time with supervisor 2 years $(M=2.67)$. The employers that were represented ranged from small (less than 100 employees; $52 \%$ ) and medium (between 100 and 500 employees; 17\%) to large organizations (more than 500 employees; 31\%). Four types of industry sectors had the highest representation: educational institution $(16.8 \%)$, retail and wholesale $(15.9 \%)$, health services $(14.5 \%)$, and manufacturing (11\%). Participants were from 57 countries and territories. Only four countries exceeded $4 \%$ in frequency: China (6.2\%), India (5.5\%), Russia (4.9\%), and Mexico (4.8\%). We compared the demographic characteristics of our sample with those of foreign-born workers in the United States as reported by the U.S. BLS in 2013. Although the gender makeup is similar, the comparison shows several key differences in other areas. Specifically, by gender, men accounted for $57.7 \%$ in the BLS data, compared with $55 \%$ in our sample. In the BLS data, Hispanics accounted for $47.8 \%$ of the foreign-born workers, compared with $11.8 \%$ in our sample. The educational level shown in the BLS data was lower than that in our sample. For example, $33.8 \%$ in the BLS data had a bachelor's degree or higher, compared with $46.8 \%$ in our sample; $17.1 \%$ in the BLS data had some college, compared with $34.8 \%$ in our sample. In addition, by age, the proportion of the foreign-born labor force in the age bracket between 25 and 54 years (74.6\%) in the BLS data was higher than that in our sample $(60.2 \%)$. Thus, the differences in the demographic makeup have implications on the generalizability of our findings, which we address later in the study.

\section{Measurement Instruments}

Role Stressors. We adopted the 13-item scale for role stressors by Peterson et al. (1995). Although several measurement instruments of role stressors exist in the literature, the one by Peterson et al. (1995) went through a series of tests in cross-cultural settings and was, therefore, suitable for this sample. Its dimensional structure is the same as conceptualized by Kahn et al. (1964), including role ambiguity, role conflict, and role overload. A sample item for role ambiguity states, "I have clear planned goals and objectives for my job"; for role conflict, "I often get involved in situations in which there are conflicting requirements"; for role overload, "my workload is too heavy." A 7-point Likert-type scale was used from 1 being strongly disagree to 7, strongly agree. To facilitate analysis and interpretation, we reverse-coded the items of role ambiguity so that greater numbers indicate greater levels of perceived stress. 
Because of the multidimensional nature of the instrument, we conducted a confirmatory factor analysis in order to test its structural fit with the present data and to construct the measure accordingly. An initial confirmatory factor analysis showed that the factor structure has an imperfect, but adequate fit with the data, $\chi^{2}=119.22(62$, $N=145)$, comparative fit index $(\mathrm{CFI})=.95$, root mean square error of approximation $($ RMSEA $)=.08$ (Byrne, 2010; Hu \& Bentler, 1999). Modification indices suggested covariance of two pairs of error terms. After the modification, the model achieved very good fit, $\chi^{2}=73.73(60, N=145), \mathrm{CFI}=.99, \mathrm{RMSEA}=.04$. This result was consistent with that in Peterson et al. (1995). Based on the confirmed factor structure, the measurement was constructed for role ambiguity with five items $(\alpha=.88)$, role conflict with three items $(\alpha=.80)$, and role overload with five items $(\alpha=.90)$.

LMCQ. To measure LMCQ, we adopted the nine-item LMCQ scale (Jian et al., 2014) and it was found to have sound psychometric properties $(\alpha=.96)$. The scale employs a 7-point Likert-type scale from 1 being strongly disagree to 7, strongly agree. An example of the items includes, "My supervisor and I interpret each other's ideas accurately when discussing work-related matters."

Communication Frequency. We adopted a four-item instrument $(\alpha=.89)$ to measure communication frequency (Kacmar et al., 2003). A sample item states, "How often do you and your supervisor talk at work?" Participants responded on a 7-point scale from 1 being once or twice in the last 6 month to 7, many times daily.

Control Variables. We included the following control variables in the regression analyses: age, sex, member's tenure with the leader, perceived similarity with the leader, and perceived English language proficiency. First, previous research has suggested the effects of age and sex on perceived role stressors (Jian, 2014; Peterson et al., 1995; Vagg, Spielberger, \& Wasala, 2002). Second, because our study involved a relational dimension between participants and their leaders, we controlled for perceived similarity between participants and their leaders with six items $(\alpha=.94)$. Its inclusion was based on research that draws on similarity-attraction theory (Byrne, 1971), suggesting that perceived similarity in a relationship has significant predictive effects on relational outcomes (Kacmar, Harris, Carlson, \& Zivnuska, 2009; Liden, Wayne, \& Stilwell, 1993). Finally, because of the immigrant sample, we controlled for participants' perceived English language proficiency. We adopted a four-item instrument $(\alpha=.96)$ measuring perceived language proficiency (Lim, Liow, Lincoln, \& Chan, 2008) with regard to understanding, speaking, writing, and reading English. Participants responded on a 7-point scale from 1 being very few words to 7, native proficiency.

\section{Data Analysis}

For preliminary analyses, we calculated univariate statistics and conducted correlational analyses. For primary analyses, we employed hierarchical regression analyses to test Hypotheses 1, 2, and 3. Specifically, we entered the control variables in Step 1, 
Table I. Means, Standard Deviations, and Correlations.

\begin{tabular}{lcccccccccccc}
\hline Variables & 1 & 2 & 3 & 4 & 5 & 6 & 7 & 8 & 9 & $M$ & $S D$ & $n$ \\
\hline I. RA & - & & & & & & & & & 2.56 & 1.25 & 136 \\
2. RC & -.11 & - & & & & & & & & 3.52 & 1.60 & 139 \\
3. RO & -.10 & $.78^{* * * *}$ & - & & & & & & & 3.32 & 1.62 & 137 \\
4. LMCQ & $-.46^{* * *}$ & -.06 & -.10 & - & & & & & & 5.38 & 1.26 & 138 \\
5. CF & $-.16^{\mathrm{a}}$ & -.03 & .00 & $.33^{* * *}$ & - & & & & & 5.11 & 1.37 & 143 \\
6. Age & $-.23^{*}$ & -.14 & -.07 & .17 & .14 & - & & & & 33.98 & 13.36 & 136 \\
7. Sex & -.03 & -.10 & -.05 & .00 & -.00 & .02 & - & & & - & - & 139 \\
8. TWL & $-.24^{* *}$ & .03 & .01 & .08 & .11 & $.46^{* * *}$ & -.14 & - & & 31.98 & 45.25 & 145 \\
9. PS & $-.35^{* * *}$ & .03 & .01 & $.84^{* * * *}$ & $.38^{* * *}$ & $.22^{*}$ & .07 & .07 & - & 4.79 & 1.37 & 138 \\
10. PLP & .05 & .03 & -.10 & .15 & .07 & $-.16^{*}$ & .05 & -.03 & .13 & 5.96 & 1.17 & 145 \\
\hline
\end{tabular}

Note. $\mathrm{RA}=$ Role Ambiguity; $\mathrm{RC}=$ Role Conflict; $\mathrm{RO}=$ Role Overload; $\mathrm{LMCQ}=$ Leader - Member Conversational Quality; CF = Communication Frequency; TWL = Tenure with Leader; $\mathrm{PS}=$ Perceived Similarity; PLP = Perceived Language Proficiency.

ap $=.06$.

$* p<.05 . * * p<.01 . * * * p<.001$ (two-tailed).

including age, sex, time with supervisor, perceived similarity, and perceived language proficiency. In Steps 2 and 3, we entered communication frequency and LMCQ, respectively.

To test Hypotheses 4, 5, and 6, we used Hayes's (2014) PROCESS macro for SPSS to test the moderation effects and to further probe the moderation. Hayes's PROCESS macro commands automatically calculate the product term (LMCQ $\times$ Communication Frequency) and estimate the moderation models. Using PROCESS has one additional advantage, which is the choice of using a percentile approach to generate visual representations of moderation effects and estimate simple slopes. In the past, the most common approaches include choosing one standard deviation below and above the mean, or median split or mean split, which may include values beyond the actual range of the observed values (Hayes, 2014). The percentile approach, instead, uses values of the moderator corresponding to the 10th, 25th, 50th, 75th, and 90th percentiles in the sample distribution of the moderator (Hayes, 2014). Simple slopes at these five percentile levels of the moderator were then estimated for statistical significance. Mean-centered values of the predictor variables were used for the tests of moderation.

\section{Results}

Table 1 reported the means, standard deviations, and correlations among the control, predictor, and outcome variables. Both LMCQ and communication frequency had significant negative correlations with role ambiguity. Among control variables, age, tenure with supervisor, and perceived similarity also demonstrated significant negative correlations with role ambiguity. However, none of the control or predictor variables showed significant correlations with role conflict or role overload. 
Table 2. Hierarchical Regression Analyses.

\begin{tabular}{|c|c|c|c|c|c|c|}
\hline \multirow[b]{2}{*}{ Predictors } & \multicolumn{2}{|c|}{ Role Ambiguity } & \multicolumn{2}{|c|}{ Role Conflict } & \multicolumn{2}{|c|}{ Role Overload } \\
\hline & $\Delta R^{2}$ & $\beta$ & $\Delta R^{2}$ & $\beta$ & $\Delta R^{2}$ & $\beta$ \\
\hline $\begin{array}{l}\text { Step I } \\
\quad \text { Control Variables }\end{array}$ & $.16 * * *$ & & .09 & & .05 & \\
\hline Step 2 & .00 & & .00 & & .00 & \\
\hline CF & & -.04 & & -.03 & & .05 \\
\hline Step 3 & $.07 * *$ & & $.03^{b}$ & & $.04 *$ & \\
\hline LMCQ & & $-.50 * *$ & & $-.29 b$ & & $-.38 *$ \\
\hline Step $4^{c}$ & .00 & & $.04 *$ & & .02 & \\
\hline $\mathrm{LMCQ} \times \mathrm{CF}$ & & .01 & & $-.16 *$ & & -.13 \\
\hline Total $R^{2}$ & \multicolumn{2}{|c|}{.24} & \multicolumn{2}{|c|}{.15} & \multicolumn{2}{|c|}{.12} \\
\hline$n$ & \multicolumn{2}{|c|}{122} & \multicolumn{2}{|c|}{121} & \multicolumn{2}{|c|}{121} \\
\hline
\end{tabular}

Note. $\mathrm{LMCQ}=$ Leader-Member Conversational Quality; CF = Communication Frequency. ${ }^{a}$ Control variables include age, sex, tenure with leader, perceived similarity, and perceived language proficiency. ${ }^{b} p=.07$. 'Step 4 model was tested through Hayes's (2014) PROCESS macro for SPSS. $*_{p}<.05 . * * p<.01$. *** $*_{p}<.001$.

We conducted hierarchical regression analyses to test Hypotheses 1, 2, and 3 regarding the predictive effects of LMCQ on role ambiguity, role conflict, and role overload, respectively. Table 2 presented the results from these analyses. First, for role ambiguity, Hypothesis 1 states that LMCQ is significantly associated with role ambiguity. Results showed that Step 3 model was statistically significant over and above Step 2 model $\left(\Delta R^{2}=.07, \Delta F=11.09, p<.01\right)$ and that LMCQ $(\beta=-.50, p<.01)$ was a significant predictor of role ambiguity over and beyond the effects of control variables and communication frequency. Therefore, Hypothesis 1 was supported. Hypothesis 2 states that LMCQ is significantly associated with role conflict. Statistical testing showed that Step 3 model was only marginally significant over and above Step 2 model $\left(\Delta R^{2}=.03, \Delta F=3.41, p=.07\right)$ and the effect of LMCQ $(\beta=-.29, p=.07)$ approached statistical significance. Thus, Hypothesis 2 was not strongly supported. Hypothesis 3 predicts that LMCQ is significantly associated with role overload. Statistical results demonstrated that Step 3 model was significant over and above Step 2 model $\left(\Delta R^{2}=.04, \Delta F=5.53, p<.05\right)$ and the effect of LMCQ $(\beta=-.38, p<.05)$ was significant. Thus, Hypothesis 3 was supported.

Hypotheses 4, 5, and 6 predict a moderation effect of communication frequency on the association of LMCQ with role ambiguity, role conflict, and role overload, respectively. We estimated the moderation models through Hayes's (2014) PROCESS macro for SPSS. For Hypothesis 4 with regard to role ambiguity, the test demonstrated that the moderation effect of communication frequency was nonsignificant. Thus, Hypothesis 4 was not supported. For Hypothesis 5 regarding role conflict, results showed a statistically significant moderation effect of communication frequency with LMCQ $\left(\Delta R^{2}=.04, \Delta F=4.80, p<.05\right)$. For Hypothesis 6 regarding role overload, the 


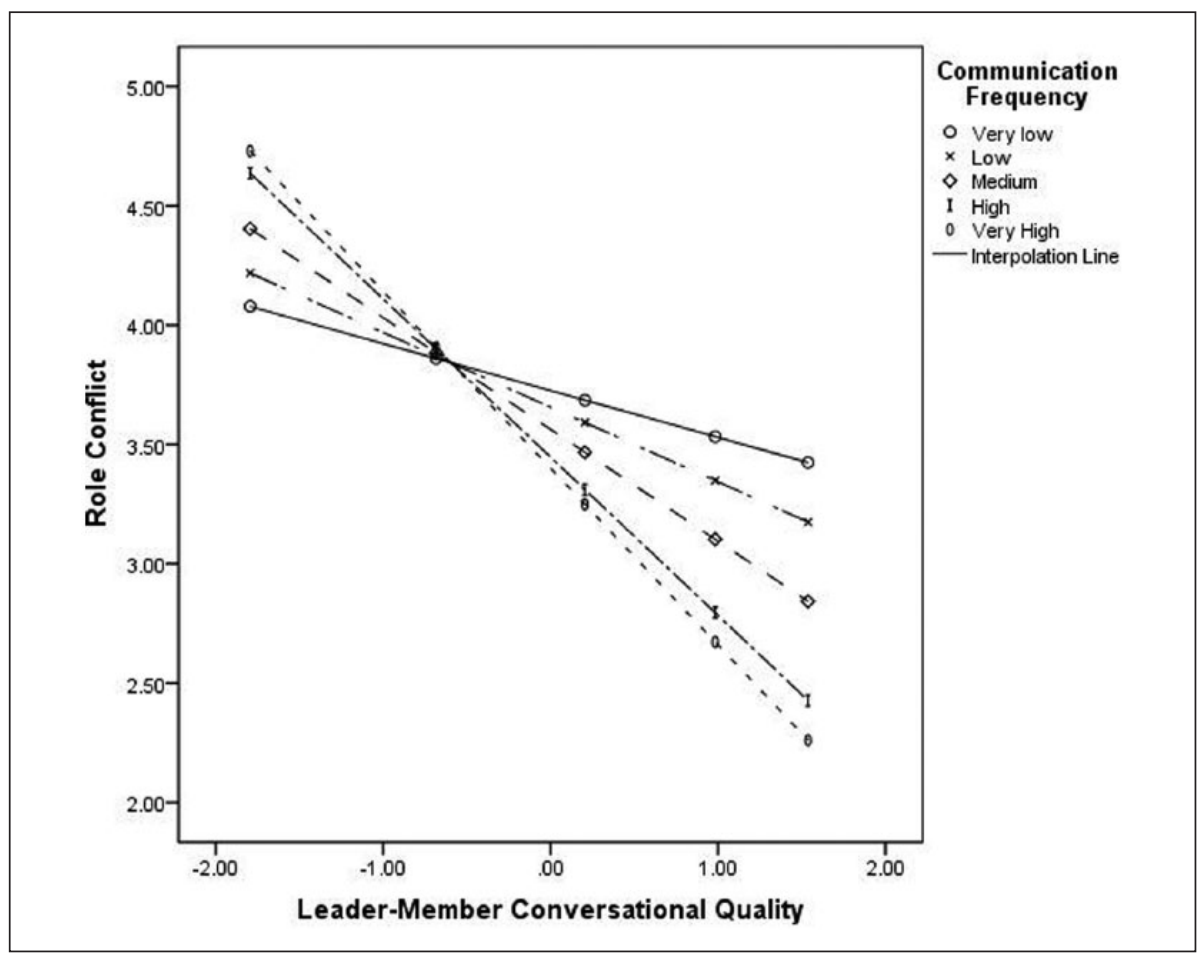

Figure 2. The moderating effect of communication frequency on the association between leader-member conversational quality and role conflict. The range of leader-member conversational quality is based on mean-centered values.

moderation effect was shown to be nonsignificant. Therefore, Hypothesis 6 was not supported.

Because the moderation effect of communication frequency on the association between LMCQ and role conflict was statistically significant, we took the next step to examine whether the relationship between LMCQ and role conflict at different levels of communication frequency was statistically significant. First, we used the percentile approach (Hayes, 2014), as discussed earlier, to produce a visual representation of the moderation effect as shown in Figure 2. It was clear that as communication frequency increased, the negative association between LMCQ and role conflict became stronger. The estimations of these simple slopes were presented in Table 3. It appears that the association was statistically nonsignificant at very low (the 10th percentile) and low (the 25th percentile) levels of communication frequency. However, at and above the medium (the 50th percentile) level of communication frequency, the negative association between LMCQ and role conflict was statistically significant. The results also showed that the predictive effects of LMCQ became stronger as communication frequency increased. Based on these results, we conclude that Hypothesis 5 was supported. The results of all six hypotheses are summarized in Table 4. 
Table 3. Post Hoc Probing of the Moderating Effects of Communication Frequency on the Association between LMCQ and Role Conflict.

\begin{tabular}{lllc}
\hline Communication Frequency & Effect & SE & $t$ \\
\hline 3.50 (The 10th percentile; very low) & -.18 & .22 & -.82 \\
4.25 (The 25th percentile; low) & -.30 & .20 & -1.50 \\
5.25 (The 50th percentile; medium) & -.47 & .20 & $-2.29 *$ \\
6.25 (The 75th percentile; high) & -.63 & .23 & $-2.73^{* *}$ \\
7.00 (The 90th percentile; very high) & -.76 & .26 & $-2.85^{* *}$ \\
\hline
\end{tabular}

Note. $\mathrm{LMCQ}=$ Leader-Member Conversational Quality.

$*_{p}<.05 . * * p<.01$.

Table 4. Results Summary.

\begin{tabular}{lll}
\hline Hypotheses Results & Res \\
\hline
\end{tabular}

I. Member-perceived conversational quality in a leader-member dyad is negatively associated with the member's perceived role ambiguity.

2. Member-perceived conversational quality in a leader-member dyad is negatively associated with the member's perceived role conflict.

3. Member-perceived conversational quality in a leader-member dyad is negatively associated with the member's perceived role overload.

4. The association between LMCQ and member perception of role ambiguity is on the condition of leader-member communication frequency, such that the association is stronger when communication frequency is high than when communication frequency is low.

5. The association between LMCQ and member perception of role conflict is on the condition of leader-member communication

Not supported

Supported

Not supported frequency, such that the association is stronger when communication frequency is high than when communication frequency is low.

6. The association between LMCQ and member perception of role overload is on the condition of leader-member communication frequency, such that the association is stronger when communication frequency is high than when communication frequency is low.

\section{Discussion}

In recent years, scholars call for studies of more precise mechanisms by which leadership is associated with employee psychological health outcomes (Macik-Frey et al., 2007). The present investigation responded to the call by conceptualizing and testing the association between leader-member communication practices and employee work role stressors. The study contributes to the current literature in several ways.

First, as hypothesized, it was found that the quality of conversations perceived by members with their leaders has a significant negative association with member perceived role ambiguity and role overload. In work contexts, higher quality conversations with a leader possess greater "carrying capacity" (Barry \& Crant, 2000, p. 651) 
and tend to provide more clarity and precision on what expectations are with regard to a given role. It was interesting to find that communication frequency plays a nonsignificant moderating role in this relationship. That is, the significant associations between conversational quality and perceived role ambiguity and role overload maintain regardless of the frequency of communication between the two parties.

By contrast, the findings showed that the association between conversational quality and role conflict depends on the communication frequency between leaders and members. Specifically, when communication frequency is at low levels, the association is statistically nonsignificant. That is, when leaders and members talk infrequently, conversational quality does not show predictive effects on member's perception of role conflict. However, when the two parties communicate at medium or higher levels of frequency, not only is there a significant negative association of conversational quality with member's perception of role conflict but also the association turns stronger as communication becomes more frequent. To make sense of this result, we need to take a closer look at the construct of role conflict. Unlike role ambiguity and overload, role conflict is a stressor that could be the result of more complex processes such as organizational politics or increasingly complex organizational structure, such as a matrix organization. For example, a conflict in role could be the result of receiving demands from two role senders: a supervisor that a subordinate routinely reports to and a project leader with a temporary project-based leadership role. The supervisor may collect performance information from the project leader regarding a subordinate on his or her performance reviews. The finding seems to suggest that if the communication between the supervisor and subordinate is infrequent, the dyad cannot benefit from the richness of a conversation. This may simply be because role conflict could be challenging, or more challenging than role ambiguity or overload, to communicate. One or two conversations, even with high quality, are not enough to handle the problem that a subordinate experiences with regard to role conflict. However, with frequent communication, the results suggested, the two parties would be able to benefit from quality conversations resulting in lower perceptions of role conflict. Weick's (1995) sense-making theory provides a useful lens to comprehend the results. According to Weick, work situations that cause stress and anxiety tend to trigger sensemaking by organizational members as a way to cope with stress. Conversations with leaders, we argue, are an important part of the sense-making process. Unlike role ambiguity, which can be clarified through quality conversations alone, role conflict can be more challenging to make sense and require both quality and frequent conversations. With infrequent communication, a few high-quality conversations may not help lower the perception of role conflict.

In summary, these findings have important theoretical implications. First, they extended the theory of role dynamics (Glazer \& Beehr, 2005; Kahn \& Byosiere, 1990; Tordera et al., 2008) by identifying specific communication practices that could have differential predictive effects on perceived role stressors. Second, previous research tends to draw broad connections between leadership styles and follower psychological outcomes (Macik-Frey et al., 2007). By contrast, this study reveals more specific mechanisms by which leadership communication may function in relation to work role stressors. Our findings offer more specificity in theoretical development and targeted intervention in practice. 
Yet this study has a number of limitations. First of all, although the moderating effect of communication frequency on the association between LMCQ and role conflict was shown to be statistically nonsignificant when communication frequency was below the medium level, this finding could be the result of low statistical power due to small subsample sizes, which increased the chance of Type II error in significance testing. Future research can retest the hypotheses with larger sample sizes. Second, the study was unable to collect and measure real-time conversational data. Instead, we relied on selfreported data, that is, subordinate perception of conversational quality of leader-member dyads. Although perceptions of behavior have its own unique theoretical value, real-time conversational data would certainly enrich the overall understanding of behavior and its consequences. Third, the study employed a network sample of foreignborn workers in the United States. As mentioned earlier, the demographic characteristics of our sample showed major differences with those in the BLS data. Thus, the findings' generalizability is limited by the sampling technique. In addition, whether the findings apply to native working population also demands further research. Fourth, due to the cross-sectional survey design, no causal relationship can be drawn from the findings. In fact, the relationship between communication practices and role stressors is most likely recursive. For example, it is plausible that greater role stressors could cause a member to avoid interaction with his or her leader in order to prevent further stress (Kahn et al., 1964). This lack of interaction could further inhibit opportunities for role clarifications, thus, exacerbating the perception of role stressors. Hence, only a longitudinal investigation would be able to reveal such a recursive pattern. Finally, the scope of the study is limited in the sense that leaders are one of many potential role senders in the overall role set of a position. For example, research has shown that teamwork contributes to the perception of role stress (Savelsbergh, Gevers, van der Heijden, \& Poell, 2012). Hence, how and to what degree conversations function in relation to stress could be investigated in conjunction with other role sender-receiver relationships.

In addition to the theoretical implications and methodological limitations we have discussed so far, the findings have significant practical implications. First, the study emphasizes the importance of quality, instead of frequency, of conversations in dealing with role ambiguity and overload. Both managers and employees should strive for accuracy, efficiency, and coordination in conversations. To deal with role conflict, leaders should provide more opportunities for quality conversations with members. Very few conversations, even with good quality, do not help fulfill the need of sensemaking on the part of employees in situations of role conflict. The study suggests both frequent and quality conversations to deliver the effect of a reduced sense of role conflict.

\section{Declaration of Conflicting Interests}

The author(s) declared no potential conflicts of interest with respect to the research, authorship, and/or publication of this article.

\section{Funding}

The author(s) received no financial support for the research, authorship, and/or publication of this article. 


\section{References}

Antón, C. (2009). The impact of role stress on workers' behavior through job satisfaction and organizational commitment. International Journal of Psychology, 44, 187-194.

Austin, J. L. (1962). How to do things with words. Oxford, England: Oxford University Press.

Barry, B., \& Crant, J. M. (2000). Dyadic communication relationships in organizations: An attribution/expectancy approach. Organization Science, 11, 648-664. doi:10.1287/ orsc.11.6.648.12537

Becerra, M., \& Gupta, A. K. (2003). Perceived trustworthiness within the organization: The moderating impact of communication frequency on trustor and trustee effects. Organization Science, 14, 32-44.

Boden, D. (1994). The business of talk: Organizations in action. Cambridge, England: Polity Press.

Britt, T. W., Davison, J., Bliese, P. D., \& Castro, C. A. (2004). How leaders can influence the impact that stressors have on soldiers. Military Medicine, 169, 541-545.

Byrne, B. M. (2010). Structural equation modeling with AMOS: Basic concepts, applications, and programming (2nd ed.). New York, NY: Routledge.

Byrne, D. (1971). The attraction paradigm. New York, NY: Academic Press.

Clifton, J. (2012). A discursive approach to leadership: Doing assessments and managing organizational meanings. Journal of Business Communication, 49, 148-168.

Dulebohn, J. H., Bommer, W. H., Liden, R. C., Brouer, R. L., \& Ferris, G. R. (2012). A meta-analysis of antecedents and consequences of leader-member exchange: Integrating the past with an eye toward the future. Journal of Management, 38, 1715-1759. doi: $10.1177 / 0149206311415280$

Fairhurst, G. T. (1993). The leader-member exchange patterns of woman leaders in industry: A discourse analysis. Communication Monographs, 60, 321-351. doi:10.1080/03637759309376316

Fox, M. L., Dwyer, D. J., \& Ganster, D. C. (1993). Effects of stressful job demands and control on psychological and attitudinal outcomes in a hospital setting. Academy of Management Journal, 36, 289-318.

Gajendran, R. S., \& Joshi, A. (2012). Innovation in globally distributed teams: The role of LMX, communication frequency, and member influence on team decisions. Journal of Applied Psychology, 97, 1252-1261.

Gerstner, C., \& Day, D. (1997). Meta-analytic review of leader-member exchange theory: Correlates and construct issues. Journal of Applied Psychology, 82, 827-844.

Gilboa, S., Shirom, A., Fried, Y., \& Cooper, C. (2008). A meta-analysis of work demand stressors and job performance: Examining main and moderating effects. Personnel Psychology, $61,227-271$.

Glazer, S., \& Beehr, T. A. (2005). Consistency of implications of three role stressors across four countries. Journal of Organizational Behavior, 26, 467-487.

Graen, G. B., \& Uhl-Bien, M. (1995). Relationship-based approach to leadership: Development of a leader-member exchange (LMX) theory of leadership over 25 years-Applying a multilevel multi-domain perspective. Leadership Quarterly, 6, 219-247. doi:10.1016/10489843(95)90036-5

Hayes, A. F. (2014). Introduction to mediation, moderation, and conditional process analysis: A regression-based approach. New York, NY: Guilford Press.

Hu, L-T., \& Bentler, P. M. (1999). Cutoff criteria for fit indexes in covariance structure analysis: Conventional criteria versus new alternatives. Structural Equation Modeling, 6, 1-55. 
Jian, G. (2011). Articulating circumstance, identity, and practice: Toward a discursive framework of organizational changing. Organization, 18, 45-64.

Jian, G. (2014). Revisiting the association between LMX quality with perceived role stressors: Evidence of inverted-U relationship among immigrant employees. Communication Research, 41, 52-73.

Jian, G., Shi, X., \& Dalisay, F. (2014). Leader-member conversational quality: Scale development and validation through three studies. Management Communication Quarterly. Advance online publication. doi:10.1177/0893318914533201

Kacmar, K. M., Harris, K. J., Carlson, D. S., \& Zivnuska, S. (2009). Surface-level actual similarity vs. deep-level perceived similarity: Predicting leader-member exchange agreement. Journal of Behavioral \& Applied Management, 10, 315-334.

Kacmar, K. M., Witt, L. A., Zivnuska, S., \& Gully, S. M. (2003). The interactive effect of leader-member exchange and communication frequency on performance ratings. Journal of Applied Psychology, 88, 764-772. doi:10.1037/0021-9010.88.4.764

Kahn, R. L., \& Byosiere, P. (1990). Stress in organizations. In M. D. Dunnette \& L. M. Hough (Eds.), Handbook of industrial and organizational psychology (Vol. 3, pp. 571-650). Palo Alto, CA: Consulting Psychologists Press.

Kahn, R. L., Wolfe, D. M., Quinn, R. P., \& Snoek, J. D. (1964). Organizational stress: Studies in role conflict and ambiguity. New York, NY: Wiley.

Kouvonen, A., Kivimäki, M., Väänänen, A., Heponiemi, T., Elovainio, M., Ala-Mursula, L., . . . Vahtera, J. (2007). Job strain and adverse health behaviors: The Finnish Public Sector Study. Journal of Occupational and Environmental Medicine, 49, 68-74.

Liden, R. C., Wayne, S. J., \& Stilwell, D. (1993). A longitudinal study on the early development of leader-member exchanges. Journal of Applied Psychology, 78, 662-674.

Lim, V. P. C., Liow, S. J. R., Lincoln, M., \& Chan, Y. H. (2008). Determining language dominance in English-Mandarin bilinguals: Development of a self-report classification tool for clinical use. Applied Psycholinguistics, 29, 389-412.

Lyons, J. B., \& Schneider, T. R. (2009). The effects of leadership style on stress outcomes. The Leadership Quarterly, 20, 737-748.

Macik-Frey, M., Quick, J. C., \& Nelson, D. (2007). Advances in occupational health: From a stressful beginning to a positive future. Journal of Management, 33, 809-840.

Mayfield, J., \& Mayfield, M. (2006). The benefits of leader communication on part-time worker outcomes: A comparison between part-time and full-time employees using motivating language. Journal of Business Strategies, 23, 131-153.

Mayfield, J., \& Mayfield, M. (2009). The role of leader motivating language in employee absenteeism. Journal of Business Communication, 46, 455-479.

Mayfield, J., \& Mayfield, M. (2012). The relationship between leader motivating language and self-efficacy: A partial least squares model analysis. Journal of Business Communication, 49, 357-376.

Miller, K. I., Ellis, B. H., Zook, E. G., \& Lyles, J. S. (1990). An integrated model of communication, stress and burnout in the workplace. Communication Research, 17, 300-326.

Nissly, J. A., Mor Barak, M. E., \& Levin, A. (2005). Stress, social support, and workers' intentions to leave their jobs in public child welfare. Administration in Social Work, 29(1), 79-100.

Nixon, A., Mazzola, J., Bauer, J., Krueger, J., \& Spector, P. (2011). Can work make you sick? A meta-analysis of the relationship between job stressors and physical symptoms. Work \& Stress, 25(1), 1-22. 
Perrewé, P. L., \& Ganster, D. C. (Eds.). (2006). Employee health, coping and methodologies. Amsterdam, Netherlands: Elsevier/JAI.

Perrewé, P. L., \& Ganster, D. C. (2010). Research in occupational stress and well-being. Amsterdam, Netherlands: Elsevier/JAI.

Peterson, M. F., Smith, P. B., Akande, A., Ayestaran, S., Bochner, S., Callan, V., . . Viedge, C. (1995). Role conflict, ambiguity, and overload: A 21-nation study. Academy of Management Journal, 38, 429-452.

Ray, E. B., \& Miller, K. I. (1991). The influence of communication structure and social support on job stress and burnout. Management Communication Quarterly, 4, 506-527.

Rizzo, J. R., House, R. J., \& Lirtzman, S. I. (1970). Role conflict and ambiguity in complex organizations. Administrative Science Quarterly, 15, 150-163.

Rosen, C. C., Chang, C-H., Djurdjevic, E., \& Eatough, E. (2010). Occupational stressors and job performance: An updated review and recommendations. In P. L. Perrewe \& D. C. Ganster (Eds.), New developments in theoretical and conceptual approaches to job stress, Research in occupational stress and well being (Vol. 8, pp. 1-60). Bingley, England: Emerald.

Savelsbergh, C., Gevers, J. M. P., van der Heijden, B. I. J. M., \& Poell, R. F. (2012). Team role stress: Relationships with team learning and performance in project teams. Group \& Organization Management, 37, 67-100.

Sharbrough, W. C., Simmons, S. A., \& Cantrill, D. A. (2006). Motivating language in industry: Its impact on job satisfaction and perceived supervisor effectiveness. Journal of Business Communication, 43, 322-343. doi:10.1177/0021943606291712

Sullivan, J. J. (1988). Three roles of language in motivation theory. Academy of Management Review, 13, 104-115.

Taylor, J., \& Van Every, E. J. (2000). The emergent organization: Communication as its site and surface. New York, NY: Psychology Press.

Tordera, N., González-Romá, V., \& Peiró, J. M. (2008). The moderator effect of psychological climate on the relationship between leader-member exchange quality (LMX) and role overload. European Journal of Work and Organizational Psychology, 17, 55-72.

U.S. Bureau of Labor Statistics. (2013). Foreign-born workers: Labor force characteristics-2013. Retrieved from http://www.bls.gov/news.release/pdf/forbrn.pdf

Vagg, P. R., Spielberger, C. D., \& Wasala, C. F. (2002). Effects of organizational level and gender on stress in the workplace. International Journal of Stress Management, 9, 243-261.

Weick, E. K. (1995). Sensemaking in organizations. Thousand Oaks, CA: Sage.

\section{Author Biographies}

Guowei Jian ( $\mathrm{PhD}, 2003$, University of Colorado at Boulder) is an associate professor in the School of Communication at Cleveland State University, USA. He studies organizational communication, leadership, and organizational change.

Francis Dalisay ( $\mathrm{PhD}, 2010$, Washington State University) is an assistant professor of the Communication and Fine Arts Department at the College of Liberal Arts and Social Sciences in the University of Guam, Mangilao, GU. His research interests include communication effects and processes in the Pacific Rim and international contexts. 